\title{
Erratum to: Long-term intraocular pressure changes after combined phacoemulsification, intraocular lens implantation, and vitrectomy
}

\author{
Yuya Ki-I · Takehiro Yamashita • Akinori Uemura • \\ Taiji Sakamoto
}

Published online: 13 March 2013

(C) Japanese Ophthalmological Society 2013

Erratum to: Jpn J Ophthalmol (2013) 57:57-62

DOI 10.1007/s10384-012-0207-7

The authors of the above-mentioned article would like to make the following change.

In the "Materials and methods" section of the article, the first sentence should read:

The study was carried out with the approval of the Institutional Review Board of Kagoshima City Hospital and was performed in accordance with the ethical standards laid down by the 1989 Declaration of Helsinki.

The online version of the original article can be found under doi:10.1007/s10384-012-0207-7.

Y. Ki-I · T. Yamashita · A. Uemura · T. Sakamoto $(\bowtie)$ Department of Ophthalmology, Kagoshima University Graduate School of Medical and Dental Sciences, 8-35-1 Sakuragaoka, Kagoshima 890-8520, Japan

e-mail: tsakamot@m3.kufm.kagoshima-u.ac.jp

Y. Ki-I · A. Uemura

Kagoshima City Hospital, Kagoshima, Japan 